\title{
Tetracycline: Classification, Structure Activity Relationship and Mechanism of Action as a Theranostic Agent for Infectious Lesions-A Mini Review
}

\author{
Saleha Tariq, Syed Faheem Askari Rizvi* and Ummar Anwar \\ Department of Chemistry, Government College University Faisalabad-38000, Pakistan
}

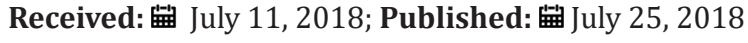

*Corresponding author: Syed Faheem Askari Rizvi, Department of Chemistry, Government College University Faisalabad- 38000 , Pakistan,

\begin{abstract}
Infectious diseases are a major cause of threat throughout the world which may have concern with microorganisms, specifically bacteria. Various antibiotics are synthesized and used against infectious diseases to mimic the death rate. The tetracyclines are a broad spectrum antibiotics discovered as natural products with exclusive biological and chemical properties against both gram-positive/negative bacteria. Many of members of this family also possess some non-antibacterial properties such as anti-inflammatory, immunosuppressant and inhibition of lipase. Various studies reveals structure activity relationship of the tetracycline family, which shows the bioactivity, strength and selectivity to biological target, specifically depends upon modification of lower and upper peripheral zones of tetracycline skeleton. The broad spectrum antibacterial activities of tetracyclines drag the attention toward labeling of tetracycline with radioisotopes for imaging of infectious lesions. For labeling purposes, optimization conditions, characterization, in-vivo and in-vitro studies are essential parameters to be studied. In clinical practice, tetracycline and three of its analogs were labeled with technetium-99m ( Tc-99m) used as diagnostic agents for renal and myocardial abnormalities as well as for inflammatory disorders Graphical Abstract.
\end{abstract}

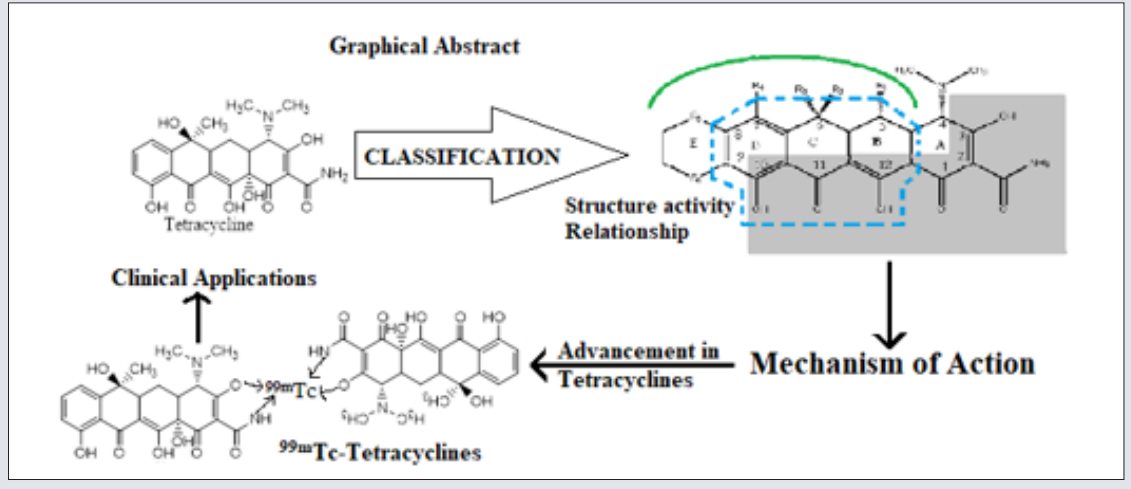

Graphical Abstract

Keywords: Tetracyclines; Antibacterial; Anti-Inflammatory; Immune-suppressant; Structure Activity Relationship

\section{Introduction}

Infection is a complex mechanism caused by the entrance of living microbes (bacteria, fungi and viruses) and other factors such as traumatism, physical and chemical agents which cause infection. Large number of infectious diseases causes worldwide death, so early stage diagnosis may help to reduce morbidity and mortality. Diagnosis of infectious disease involves the identification of the root cause of infectious disorders. In spite of having many advanced techniques to identify and treat infectious lesions, the world is facing a great threat of infectious diseases which is deleterious.
The attention of worldwide scientists in search of antibiotic drugs was diverted after the announcement of Alexander Fleming's discovery regarding penicillin. Various families of antibiotics have been discovered up till now and categorized based on their mechanism of action, chemical structure, or spectrum of activity. Some antibiotics have bactericidal activities to attack on the bacterial cell wall and bacterial cell membrane such as penicillins, vancomycin, isoniazid and cephalosporins polymyxins, while some antibiotics do their work by inhibiting DNA and RNA synthesis such 
as actinomycin, nucleotide analogs or hold up the essential bacterial enzymes like rifamycins, lipiamycins, quinolones and sulfonamides.

Target specificity is another way of classification, according to which antibiotics are classified into two main groups, narrow spectrum and broad spectrum. Narrow spectrum antibiotics target specific type of bacteria such as gram positive/negative bacteria, whereas broad spectrum antibiotics act against a wide range of disease causing bacteria such as ampicillin, which is used to prevent and treat number of bacterial infections including respiratory and urinary tract infections, meningitis, salmonella infection and endocarditis [1]. Government sponsored research and development program to promote the growth of antibiotic's research. In order to contribute toward this research in mid of 1940s a 71 years old Benjamin Minge Duggar head of the soil engineering department identified tetracycline as a therapeutic substance produced by soil microorganisms. At early stages, tetracycline was first originated as a fermentation product of golden colored soil bacterium named Streptomyces aureofacians [2]. This discovery led to many natural and semi-synthetic derivatives that expanded the spectrum of activity. Tetracycline is a class of antibiotics biologically effective and commercially available for the treatment and prevention of growth of gram positive/negative bacteria and intercellular chlamydiae, mycoplasmas and rickettsiae. It has bactericidal (destroy the bacteria) or bacteriostatic (hinder the reproduction and growth of bacteria) potential, extensively used as antibiotics for human and veterinary use [3]. They possess exclusive biological and chemical characteristics to work equally against prokaryotes and eukaryotes bacteria by interacting with different cellular targets and receptors [4]. They are very vibrant molecules because of their use in the field of neurology, oncology and virology [2]. Tetracycline is one of the cheapest classes of antibiotics, abundantly used in developing countries with limited health care budgets and have a number of non-antibacterial effects, including anti-inflammatory, immunosuppression, inhibition of lipase and collagenase activity and wound healing [5-7].

In this article our focus is on the class of tetracycline which behaves as typical and atypical antibiotics. The typical tetracyclines such as tetracyclines, doxycyclines, minocyclines and chlortetracyclines are bacteriostatic antibiotics which inhibit the synthesis of protein by binding with ribosomal subunits. Other tetracyclines have atypical mechanism which works as bactericidal by killing bacteria. These are very toxic for both prokaryotes and eukaryotes. Atypical tetracyclines disrupt cell membrane; inhibit all cellular processes and macromolecules synthesis pathways. Furthermore both typical and atypical tetracyclines have pharmacological effects against eukaryotic cells across multiple cell types [8].

In the late 1940s and early 1950s, tetracyclines were recognized because of their broad spectrum antibacterial activity and became commercialized with clinical success. In this class, the first discovered antibiotic was aureomycin (chlortetracycline) named in reference to its yellow color and golden colored streptomyces strain from which it is extracted [9]. Within a short time another antibiotic terramycin (oxytetracycline) was discovered by Alexander Finlay and colleagues in 1950 [10]. This medicine gained remarkable success in the treatment of broad spectrum of infectious diseases. After some modification in the structure of aureomycin, a new compound of higher potency, with a better solubility profile and favorable pharmacological activity; was subsequently named, tetracycline [9]. In short, modifications in the structure of these drugs led to the discovery of other members of this family (Figure 1).

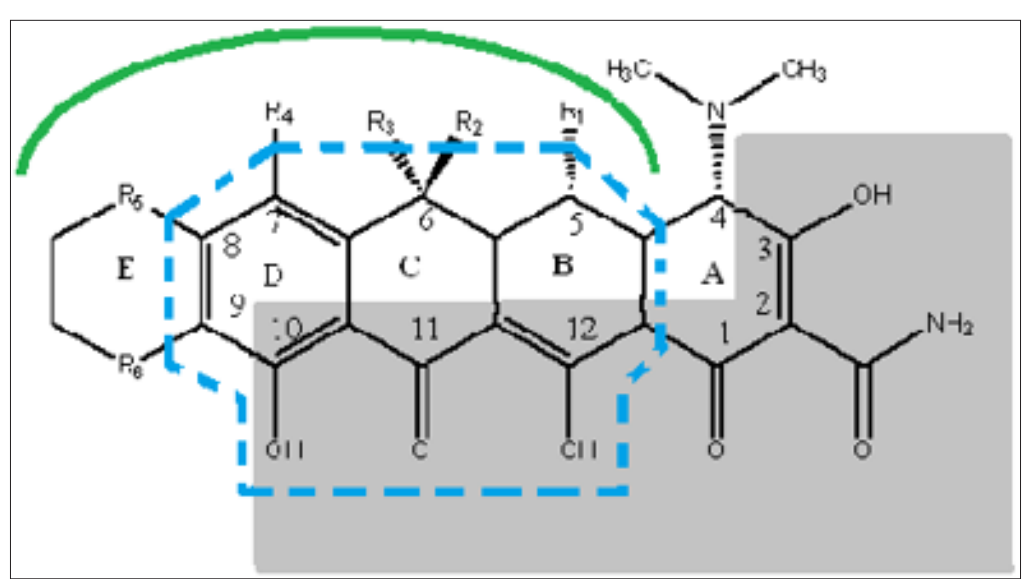

Figure 1: Structure-Activity-Relationship of Tetracyclines. Shaded: Contact region of $30 \mathrm{~S}$ rRNA. In blue polygonal: same anthracycline region [32].

Pfizer chemists, led by Robert Blackwood, chose a disjunctive approach, modifying the C-ring of oxytetracycline to afford chemical stability, where halogenations and C6-dehydration yielded the antibiotic methacycline [11]. It was further used as starting material by Charlie Stephens to produce an analog with remarkable antibiotic activity, stability and pharmacological efficacy; doxycycline [12]. One bioengineered strain by Lederle scientist formed a new member of tetracycline called demeclocycline [13] which possess unique C6 and C7 bioactive functional groups. Another analog possessing a C7-dimethylamine group was found to exhibit far greater antibacterial and pharmacological activity against a large range of bacteria called minocycline [9]. 
Furthermore, a C4 dimethylamino group with its natural 4S isomer is required for optimal antibacterial activity [14]. Wyeth launched a program to chemically modify the minocycline scaffold, producing C9-amino derivative possessing amide functionality with a glycine subunit attached, generating hundreds of new analogs for assay and evaluation and naming the series the glycylcline [15]. Many of the compounds were active against gram-positive/negative bacteria. Soon their first new tetracycline, tigecycline [16], entered clinical studies and were approved by FDA. The clinical uses of tigecycline may also expand into immunity acquired bacterial pneumonia, as it is found to be potent both in-vitro and in-vivo in patients [17].
In 1983 another scientific front evolved from tetracycline family that spread their inherent potential as mammalian therapeutics. Minocycline possess inherent and extremely potent anti-inflammatory activity that was independent of its antibacterial actions i.e inhibition collagenase activity in gram free rats, and use to treat osteoarthritis and rheumatoid arthritis in animal models [18]. One compound, doxycycline, was found to be a potent inhibitor of degradation Matrix metalloproteinase (MMP) enzyme both invitro and in-vivo and was approved by FDA for the treatment of adult periodomititis [9]. Tetracycline family specifically exhibits antibacterial, antifungal and antitumor activities shown in Table 1.

Table 1: Tetracyclines showed antibacterial, antifungal and antitumor activities [32].

\begin{tabular}{|c|c|c|c|c|}
\hline & $\begin{array}{c}1^{\text {st }} \text { Generation Natural } \\
\text { Product }\end{array}$ & $\begin{array}{l}2^{\text {nd }} \text { Generation Semi- } \\
\text { Synthetic Product }\end{array}$ & $\begin{array}{l}3^{\text {rd }} \text { Generation Synthetic } \\
\text { Product Wide Spectrum }\end{array}$ & $\begin{array}{c}\text { New } 3^{\text {rd }} \text { Generation } \\
\text { Synthetic Product Highly } \\
\text { Bacterial Specific }\end{array}$ \\
\hline $\begin{array}{l}\text { Antibacterial (Typical } \\
\text { Mechanism) Primary Target } \\
\text { is 30S/ tRNA Ribosomal }\end{array}$ & 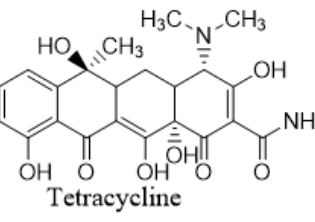 & Rolitetracycline & $\mathrm{H}_{3} \mathrm{C}_{\mathrm{CH}_{3}}^{\mathrm{H}}$ & Azatetracycline \\
\hline $\begin{array}{l}\text { Antibacterial (Atypical } \\
\text { Mechanism) Primary Target } \\
\text { is not Bacterial Ribosomal }\end{array}$ & $\overbrace{\mathrm{OH}} \prod_{\mathrm{O}}$ & 4-Epi-Anhydrochlortetracycline & Aminomethylcycline & Fluorocycline \\
\hline $\begin{array}{l}\text { Antifungal (Oxidative } \\
\text { Stress) Lonophore and } \\
\text { Chelating Mechanism }\end{array}$ & $\begin{array}{l}\mathrm{OH} \quad \mathrm{OH} \\
\quad \text { Viridicatum Toxin }\end{array}$ & $\begin{array}{c}\text { Hypomicetin } \\
\text { Hy }\end{array}$ & Not Any & Pentacycline \\
\hline $\begin{array}{l}\text { Antitumor (Multi-Target } \\
\text { Mechanism) Pro Apoptotic } \\
\text { and Oxidative Stress }\end{array}$ & Doxorubicin & $\begin{array}{l}\mathrm{OH} \text { OH OH } \\
\mathrm{CMT}-3 / \text { Metastat }\end{array}$ & 筑 & Not Any \\
\hline
\end{tabular}

Uses of tetracyclines fall into five main categories, such as antibacterial resistance [1], non-antibacterial use like inflammation [19] and arthritis [20-23], in neurology: antifibrilogenics [24], Huntington's disease [25], ischemia [26], Parkinson's [27], antiviral, anticancer [28-30] and repressor controlled gene switch [31,32]. Anti-inflammatory properties of tetracyclines include: acting as an inhibitor for lymphocytic proliferation [23], suppression of neurophilic migration [21], inhibition of phospholipase A2 [22] and accelerated degradation of nitric oxide synthesize [20].

\section{Classification of Tetracyclines}

Tetracyclines being a large family of antibiotics were discovered in the form of chlortetracycline and oxytetracycline (first members of tetracycline group) as natural products. Streptomyces aureofaciens and $S$. rimosus are the sources of chlortetracycline and oxytetracycline, respectively. Other tetracyclines were renowned later, as naturally occurring molecules from Streptomyces species of microorganisms or as derived from semi-synthetic way, for example, methacycline, doxycycline, and minocycline. In spite of the success of the early tetracyclines, analogues were demanded with improved water solubility to enhance oral absorption. These approaches lead towards the further development of semi-synthetic compounds, for example rolitetracycline and lymecycline. At the same time, another semi-synthetic group was discovered called glycylcyclines, for example 9-(N,N-dimethyl glycylamido)-6-demethyl-6-deoxytetracycline, 9-(N,N-dimethyl glycylamido)-minocycline, and 9-t-(butyl glycylamido)-minocycline [3]. Tetracycline sparked the development of many chemically altered antibiotics, and so has proved to be one of most remarkable discoveries made in the field of antibiotics.

Conventionally, tetracyclines have three generations; tetracyclines which are obtained from biosynthesis included 
in first generation, such as, chlortetecycline, oxytetracycline, demeclocycline. Second generation tetracyclines comprise of doxycycline, lymecycline, meclocycline, methacycline, minocycline, rolitetracycline obtained from semi-synthesis of tetracycline. Third generation includes tigecycline, which obtained from total synthesis. Tigecycline gives wide spectrum activity (against both gram positive/negative bacteria). In the last five years, around the world, more than 310 compounds similar to tetracycline have been synthesized, tested and patented.

\section{Structure Activity Relationship}

As the name indicates, tetracycline is an inflexible skeleton of four rings, contains many groups such as alkyl, hydroxyl and amine on the upper and lower sides of the molecule. Chemical modifications in the upper and lower regions of the structure of the tetracycline produce variably active and inactive compounds of first and second generation. Tetracycline and its analogues have basic chemical structure consisting tetracyclic naphthacene carboxamide ring system as shown in figure 1. Tetracyclines which illustrate antibiotic activity have a dimethylamine group at $\mathrm{C} 4$ in the ring A, whose existence is necessary to show antibiotic properties. Addition or removal of the dimethylamino group from $\mathrm{C} 4$ gives several chemically modified tetracyclines $[4,33]$.

The ring structure of tetracyclines contains upper and lower peripheral zones. Various chemical functional groups are attached at these zones [34]. Antibiotic and non-antibiotic characteristics of tetracyclines may be reduced by modifying the lower peripheral zone; on the other hand, modification in the upper peripheral zone enhanced the attack on biological targets, particularly at positions
C7 through C9 of the D ring. This has been lead toward the formation of semi-synthetic compounds such as minocycline and doxycycline [4].

Bioactivity, strength, selectivity to biological target and antibacterial action, specifically against Gram- positive/negative bacteria, highly depend upon modifications in the groups of lower and upper pheripheral zones of the tetracycline skeleton. An active tetracycline which demonstrates antibacterial activity must have linearly arranged DCBA naphthacene ring system with an A-ring C1-C3 diketo substructure and an exocyclic C2 carbonyl and amide group. The presence of an amino group in position $\mathrm{C} 4$ and ketoenolic tautomers in position $\mathrm{C} 1$ and $\mathrm{C} 3$ of the A ring is necessary for tetracycline to take action as inhibitor of protein synthesis. The presence of the amino group in the C4 position is vital for antibiotic activities (Figure 2). Antibacterial activity against Gram-negative bacteria may be decreased by epimerization of natural $4 \mathrm{~S}$ isomer of C4-dimethlyamino group to its $4 \mathrm{R}$ isomer (41). It also requires a C10-phenol and C11-C12 keto-enol substructure in conjunction with a 12a-OH group (scheme 1) in the lower peripheral region. Some modifications cause loss of potency like modification of amide in $\mathrm{C} 2$. Chemical modification of the positions $\mathrm{C} 5$ to $\mathrm{C} 9$ gives various derivatives of tetracyclines with varying antibacterial activities. Modification of R1, R2, R3 groups gives better selectivity to the biological target in antifungal but not for antibacterial activity. The D-ring is most flexible to change by showing antibacterial activity. All modifications of R4, R5 and R6 groups are required to give highly bacterial specificity and deep changing in pharmacokinetics (Figure 2) [35].

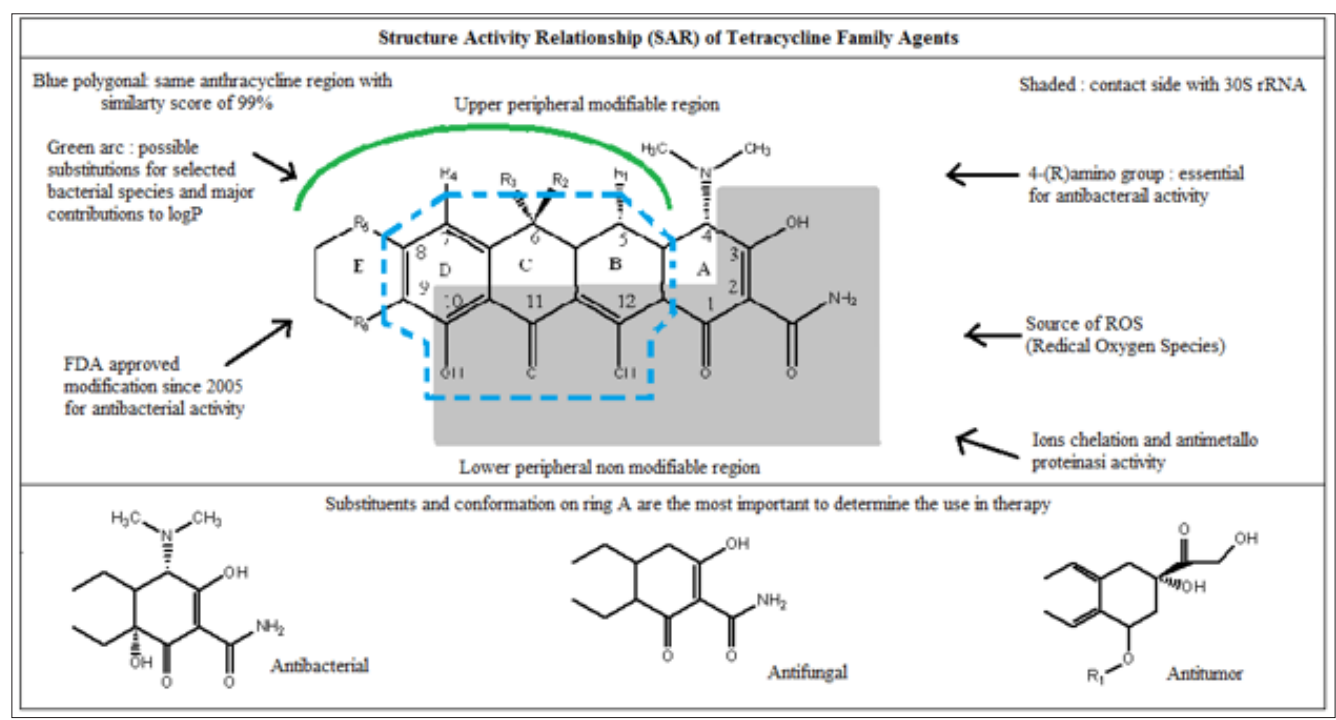

Figure 2: Structure-Activity-Relationship (SAR) of tetracycline family agents [32].

\section{Mechanism of Action}

The entire tetracycline family is biologically and chemically vibrant with multiple mechanisms of actions and is capable to act against multiple targets, either through ribosomal or cell membranes. Various mechanism of action of tetracycline is related with the attachment of different species in the skeleton such as hydroxyl and amine groups. Hydroxyl groups are source of reactive oxygen species (ROS) that remarkably break macromolecules such as DNA, RNA and protein. This breakage cause oxidative stress and ultimately death of bacterial cell. Antibacterial tetracycline act in a different way as compared to antifungal and antitumor tetracycline. 
First, tetracycline get ahead of the eukaryotic cell to form complexes in different positions with calcium and magnesium ions present in the blood by changing the electronic balance equilibrium sequestering divalent ions. In the next step, tetracycline adopt typical and atypical mechanism against bacteria either by binding with ribosomal subunits to inhibit the synthesis of protein or by the direct killing of bacteria [2].

The typical mechanism of action of tetracycline contains the prevention of the association of aminoacyl-tRNA with bacterial ribosome to inhibit bacterial protein synthesis. In gram positive and gram negative bacteria, tetracyclines intermingle with targets by passing through one or more membrane systems. Hence, mechanism of action of tetracycline requires understanding of uptake and ribosomal binding mechanism. Tetracycline crosses over the outer membrane of gram negative bacteria through outer membrane protein $\mathrm{F}$ and outer membrane protein $\mathrm{C}$ channels, as positively charged cation (mostly magnesium)-tetracycline coordination complexes. The Donnan potential of the outer membrane attract the cationic metal ion-antibiotic complex to mount up in the periplasm. At this place, metal ion-tetracycline complex probably dissociate to release uncharged tetracycline, which is a weakly lipophilic molecule efficiently and diffuse through the lipid bilayer regions of the inner (cytoplasmic) membrane. Similarly, tetracycline in electro- neutral and lipophilic forms transferred across the cytoplasmic membrane of gram positive bacteria. This uptake of tetracyclines across the cytoplasmic membrane is energy dependent. Within the cytoplasm, tetracycline molecules become chelate at specific conditions when internal $\mathrm{pH}$ and divalent metal ion concentrations are higher compared to the conditions outside the cell. Magnesium tetracycline complex is an active drug species which binds to the ribosome of the bacteria. Bacteriostatic effects of antibiotics can be explained by understanding the association of tetracycline with ribosome during reversible reaction. Pharmacokinetics and Pharmacodynamics studies of Tetracyclines

Pharmacokinetics is the study of mechanisms of absorption, distribution, chemical changes of a substance in the body and the effects, and the route of administration of metabolites of drugs in the body. Many factors affect the pharmacokinetic properties of the drugs such as site of administration and the dose of administered drug. Pharmacokinetics is often studied in combination with pharmacodynamics, which is the study of the biochemical and physiological effects of the drug on the body, or microorganisms or parasites within or on the body. The mechanism of drug action and relationship between drug concentration and effect are also studied in pharmacodynamics. Generally, tetracyclines can be divided into three main groups based on pharmacokinetics shown in Figure 3.

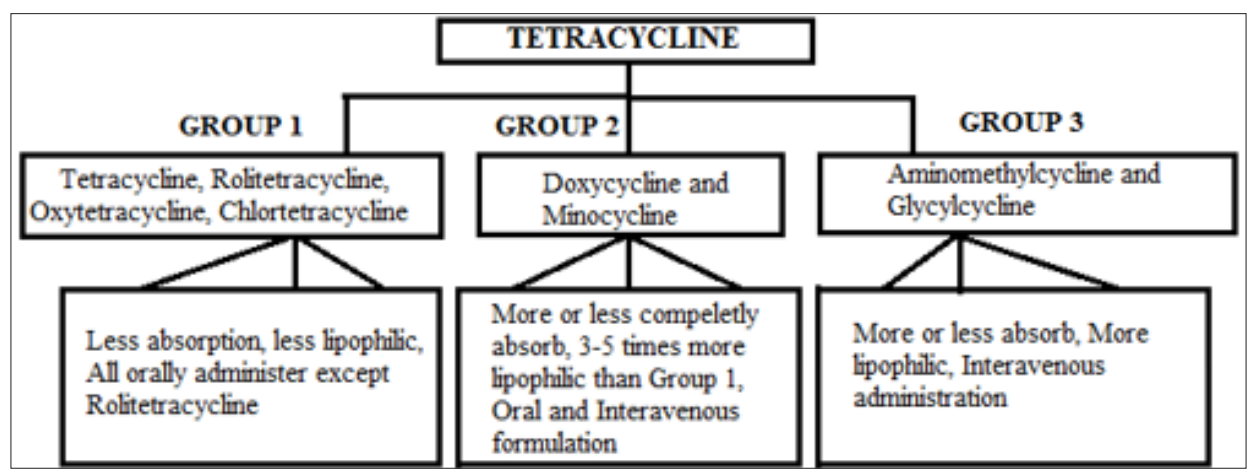

Figure 3: Groups of tetracyclines on the basis of pharmacokinetics.

Pharmacokinetics of members of the tetracycline class has been studied by using high performance liquid chromatography assays, spectrophotometric methods and biological assays. Agents of group 1 include tetracyclines, oxytetracycline, chlortetracycline, demclocycline, lymecycline and methacycline and rolitetracyclines. All members give oral formulation except rolitetracycline which gives intravenously. Absorption of most of the agents of this class is in the range of $25-60 \%$. Serum concentration progressively rises after oral administration with absorption occurring in the stomach, duodenum and small intestine. All these tetracycline reduce the absorption after forming insoluble complexes with calcium, magnesium, iron and aluminium. Furthermore, protein, fat and carbohydrate containing meals reduce the absorption of tetracycline by about 50\%, resulting in having less tissue penetration of this class, making relative distribution difficult.

Protein binding is variable. None of these agents undergo metabolism except tetracycline. Most of the members of this class (with the exception of chlortetracycline) excreted through renal and biliary routes, more than $50 \%$ of drugs excreted in urine. In all of the agents of group 1, rolitetracycline gives the highest elimination. The amount of agents excreted in faeces by biliary elimination is greater than $40 \%$. In blood, tetracycline first gives a slow rise then a slower drop, forming a plateau shaped course.

In group 2 both doxycycline and minocycline give oral formulation. Doxycycline is completely absorbed with bioavailability of more than $80 \%$ with an average of $95 \%$. Food has less effect on absorption, so more doxycycline enters the duodenum for absorption. There is little good quality tissue penetration with protein binding at $82-93 \%$. In excretory organs, concentration exceeds by giving unchanged elimination by both renal and biliary routes. About $35-60 \%$ is excreted in urine and the remainder in faeces. Minocycline is almost completely absorbed (95-100\%), mainly in the stomach, duodenum and jejunum. Iron and antacids containing calcium and magnesium reduce the absorption of minocyclines. Protein binding of minocycline is $76 \%$. Minocycline is different from other tetracycline by a giving variety of metabolites, 
in urine a little minocycline is recovered; probably out of a $5-12 \%$ dose, $20-35 \%$ is eliminated by faeces.

In group 3, two agents are included: glycylcycline and aminomethylcycline. Amino-methylcycline is in preclinical development while a little bit of pharmacokinetic data is available on tigecycline. There is no data on absorption of tigecycline, with limited data on oral formulation. Tigecycline protein binding ranges from $73 \%$ to $79 \%$. The amount of tegicycline excreted in urine is less than $15 \%$ and renal clearance is about more than $20 \%$.
Pharmacodynamics is the association between capacities of antimicrobial exposure with the antibacterial and toxicological effects of the drug in the body. Several antibacterial measures are important but the most important measure of drug potency is minimum inhibitory concentration. Generally, pharmacodynamics of tetracyclines has been understudied with few classes of drugs such as $\beta$-lactams, fluoroquinolones and aminoglycosides. The killing effects of doxycycline, minocycline and tigecycline have been studied by using the time-kill curve method (Table 2).

Table 2: Clinical data, chemical data and pharmacokinetics study of tetracyclines.

\begin{tabular}{|c|c|c|c|c|c|c|c|c|}
\hline \multirow{2}{*}{ Name of Drug } & \multirow{2}{*}{$\begin{array}{c}\text { Clinical Data } \\
\begin{array}{c}\text { Administration } \\
\text { Routes }\end{array}\end{array}$} & \multicolumn{5}{|c|}{ Pharmacokinetics } & \multicolumn{2}{|c|}{ Chemical Data } \\
\hline & & Bioavailability & $\begin{array}{l}\text { Protein } \\
\text { Binding }\end{array}$ & Metabolism & $\begin{array}{l}\text { Biological } \\
\text { Half-life }\end{array}$ & Excretion & Formula & $\begin{array}{l}\text { Molecular } \\
\text { mass }\end{array}$ \\
\hline Tetracycline & Oral, Topical & $75 \%$ & - & $\begin{array}{c}\text { Not } \\
\text { metabolized }\end{array}$ & 8-11hrs & & & \\
\hline 57-108hrs & $\begin{array}{c}\text { Urine }(\geq 60 \%), \\
\text { Feces }\end{array}$ & $\mathrm{C} 22 \mathrm{H} 24 \mathrm{~N} 2 \mathrm{O} 8$ & 444.4 & & & & & \\
\hline Chlorotetracycline & Oral, Topical & $30 \%$ & $50-55 \%$ & Hepatic & $5.6-9 \mathrm{hrs}$ & Renal, biliary & $\mathrm{C}_{22} \mathrm{H}_{23} \mathrm{ClN}_{2} \mathrm{O}_{8}$ & 478.8 \\
\hline Oxytetracycline & Oral, Ophthalmic & - & - & - & 6-8hrs & Renal & $\mathrm{C}_{22} \mathrm{H}_{24} \mathrm{~N}_{2} \mathrm{O}_{9}$ & 460.3 \\
\hline Demclocycline & Oral & $60-80 \%$ & $41-50 \%$ & Hepatic & 10-17hrs & Renal & $\mathrm{C}_{21} \mathrm{H}_{21} \mathrm{ClN}_{2} \mathrm{O}_{8}$ & 464.5 \\
\hline Doxycycline & Oral, Intravenous & $100 \%$ & $90 \%$ & Hepatic & $15-25 h r s$ & Urine $(40 \%)$ & $\mathrm{C}_{22} \mathrm{H} 24 \mathrm{~N}_{2} \mathrm{O}_{8}$ & 444 \\
\hline Lymecycline & Oral & $100 \%$ & - & - & $10 \mathrm{hrs}$ & Renal & $\mathrm{C}_{29} \mathrm{H}_{33} \mathrm{~N}_{4} \mathrm{O}_{10}$ & 597 \\
\hline Methacycline & Oral & - & - & - & - & Renal & $\mathrm{C}_{22} \mathrm{H}_{22} \mathrm{~N}_{2} \mathrm{O}_{8}$ & 442 \\
\hline Rolitetracycline & Oral & - & - & - & - & Renal & $\mathrm{C}_{27} \mathrm{H}_{33} \mathrm{~N}_{3} \mathrm{O}_{8}$ & 527 \\
\hline Minocycline & Oral & $100 \%$ & - & Liver & $11-12 \mathrm{hrs}$ & Renal, Feces & $\mathrm{C}_{22} \mathrm{H}_{27} \mathrm{~N}_{2} \mathrm{O}_{7}$ & 431 \\
\hline Tigecycline & - & - & $71-89 \%$ & $\begin{array}{c}\text { Not } \\
\text { metabolized }\end{array}$ & 42.4hrs & Biliary, Renal & $\mathrm{C}_{29} \mathrm{H}_{39} \mathrm{~N}_{5} \mathrm{O}_{8}$ & 585 \\
\hline
\end{tabular}

\section{Non-Antibiotic Properties of Tetracyclines}

Tetracycline and their analogues show non-antibiotic properties by inhibiting matrix metalloprotenases (MMP) and also play important roles in the remodeling of connective tissues and participate in wound healing; rheumatoid arthritis, tumor invasion and metastasis is also the non-antibiotic property of tetracycines [30]. Angiogenesis, construction of new blood vessels, occur in many diseases including benign (e.g rosacea) and malignant tumors (e.g cancer). Minocycline and doxycycline hold down angiogenesis induced by implanted tumors in rabbit corneas [36]. The therapeutic implication of antiangiogenic effects of tetracycline in the inflammatory process accompanied by new blood vessel formation. Furthermore, recent studies indicated that tetracycline has antiapoptotic properties [26,37]. Doxycycline and minocycline both play crucial roles in bone metabolism. Doxycycline reduces the severity of canine osteoarthritis in dog anterior cruciate model, and minocycline avert the decrease in mineral density [38] (osteoporosis) observed in ovariectomized old rats (Figure 4) [39].

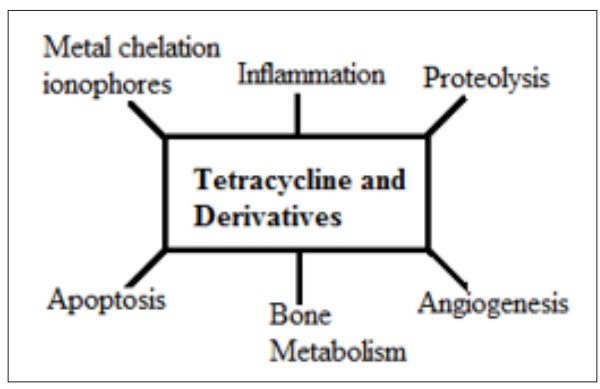

Figure 4: Different uses of Tetracycline. 
Other clinical studies include both dermatologic and nondermatologic uses of tetracyclines in the diseases of skin, bullous dermatoses, cutaneous sarcoidosis, rosacea, and sarcoidosis. Minocycline, because of having immunomodulatory and antiinflammatory properties, might be effective in the treatment of autoimmune disorders like rheumatoid arthritis, scleroderma, cancer, cardiovascular disorders and periodonititis. In short, tetracyclines and their analogues have been used not only in the treatment of different dermatologic and non-dermatologic diseases but also have anti-inflammatory and immunomodulatory effects. Because of extensive use of tetracycline, labeling of tetracycline with radioisotope was successfully done and used for the imaging of various diseases [40].

\section{Advancement in the Uses of Tetracyclines}

Conventional imaging techniques, such as radiological techniques, which includes computed tomography (CT), nuclear magnetic resonance (NMR) and ultrasonography (US) are unable to detect infection and inflammation foci in early phases of development. In contrast, incorporation of radioisotopes in drugs are able to identify the routes of administration of a drug throughout the body and are able to diagnose disease at an early stage. Scintigraphic imaging techniques (SPECT) are useful to detect pathophysilogical and pathobiological changes at an early stage of the infectious process. Over the past few years, many radiopharmaceuticals have been discovered to diagnose many infectious and non-infectious diseases [41].

Radiolabeling of molecules is significantly important, which includes visualization, characterization and quantification of tumors and their biological processes. There are basically five main, clinically used, imaging techniques: CT, ultrasound, MRI, SPECT and PET with limit of detection around 109 cells (corresponding approximately 1 gram of tissues). In therapy, particular radiations, such as alpha and beta particles and non-particulate like Auger electrons emitted by radiopharmaceuticals, are used for treatment and diagnosis. Alpha radiations give short tissue range with high localized energy deposition, which are damaging for healthy cells. Beta radiations preferentially used for therapy having low toxicity due to lower deposition energy as compared to alpha radiations. The penetration range of beta radiations is several millimeter. Thus, these radiations can easily target the cancerous cells located in the inner mass of tumors, even if penetration range of the pharmaceutical is low. Electron capture and internal conversion emit gamma radiations which further triggers emission of Auger electrons which enter only few nanometers inside tissues, where energy deposition takes place (which is significantly higher than beta radiation and lower than alpha radiations). This is the reason why non particulate emitters, such as gamma ray and positron emitter, which have low deposition energy are successfully used for therapy [42]. Tc-99m labeled compounds emit gamma radiation that's why they are using abundantly in radiopharmaceuticals, as well as it also has great importance in SPECT imaging. Currently, there are almost more than 20 discovered isotopes of technetium but the most valuable isotope is Tc-99m because of having beneficial nuclear properties, low cost of $99 \mathrm{Mo} / 99 \mathrm{mTc}$ generator and ease of availability. With all these aspects, this radioisotope $(99 \mathrm{mTc})$ has specific capabilities with favorable in vivo properties and vast clinical applications, which allow to develop radiolabeled compounds having excellent targeting properties [43].

\section{Labeling of tetracycline with Technetium-99m}

In nuclear medicine, imaging modalities, such as Gamma camera scintigraphy and PET, are abruptly used to diagnose early stage abnormalities. These kinds of techniques require a radioisotope which emits proton, neutron and Gamma radiations. Energy of these radiations are considered important to diagnose medical problems such as cancer, infection, thrombosis, kidney and liver abnormalities, cardiological and neurological disorders.

In biological distribution of radiolabeled agents, two factors must be considered:

1. Perfusion

2. Specific biochemical processes, such as receptor/ antigen binding.

Tc-99m possess ideal properties due to which it occupies an important position in nuclear medicine. In a desirable radio-metal, some important features should be considered including the halflife of radioisotope, mode of decay, cost and availability of the radioisotope. Tc-99m has a half-life of about 6 hours; long enough to carry out the desired chemistry to synthesize the radiopharmaceuticals and also long enough to allow accumulation in the target tissue, whilst allowing quick clearance through non-target organs. Another important factor is its cost and availability, for this purpose radionuclide generators are considered the best, having a longlived parent isotope that decays to a short-lived daughter radionuclide which is easily separated by simple methods like ion exchange chromatography and solvent extraction. The availability of Tc-99m whilst having a short half-life (6 hrs.) is made easily possible with a radioisotope generator at hospital level.

Energy of $\mathrm{Tc}-99 \mathrm{~m}$ is $141 \mathrm{KeV}$, which is sufficient to produce good quality images using SPECT camera. In the case of penetrating in body tissues, it gives a good target-to-non-target ratio by entering in infectious tissues. The correlation of the physical properties of radio-metal complexes with their in-vivo behavior must be considered to design radioisotope based imaging agents. Behavior of radio-metals inside the body can be detected by obtaining information like stability, stereochemistry, charge, redox properties and lipophilicity.

All these characteristics are favorably fulfilled by Tc-99m, which is the reason of its wide range of applications in radiopharmaceuticals. It leads toward the discovery of Tc-99m-radiopharmaceuticals for functional imaging [44].

Tetracycline and three of its analogs successfully labeled with Tc-99m implying a certain degree of clinical utility as renal imaging agents. These chelating agents form strong chelates with reduced 99mTc and used for further patient's studies [45]. Tc-99m labeled 
tetracycline also used for detection of actual infarct in human after studying the detection of experimentally produced myocardial infarct in dogs [46-48]. Tc-99m is not only used for diagnosis and imaging but also works as an ideal radioisotope for autoradiography of tissues of brain and bone with Tc-99m- ion and Tc-99m-polyphosphate as reported by Baum [49] and Tilden [50]. The myocardial uptake of $99 \mathrm{mTc}$ tetracycline and its analogs have been presented with good results $[45,48,51]$. The efficiency of radiopharmaceuticals is closely related to its physicochemical properties, level of toxicity, and mechanism of action against malignant diseases [52].

Doxycycline hyclate, one of the best members of tetracycline class, was obtained from modification of the oxytetracycline molecule, having bacteriostatic activity against a wide range of microorganisms. Doxycycline hyclate successfully labeled with Tc-99m and progressively applied to investigate the inflammatory lesions because of showing greater uptake in inflamed muscles, which is high enough to be distinguished from the background tissue [41].

Three pharmacologically active analogs of tetracyclines are known as chelating agents [53-55] and have been successfully labeled with Tc-99m [56], which is proficient to form large numbers of organo-metallic compounds [57]. Pharmacodynamic studies showed the biological clearance of the majority of chelates of organo-metallic complexes through urinary pathway [58,59]. These compounds are used for clinical purposes because of good organ distribution, so work well as good imaging agents for kidney and gallbladder. Tc-99m labeled tetracyclines show better pharmacodynamics as compared to other members of this class, because it has been selected for further studies. The in vivo stability of Tc-99m labeled tetracyclines in mice, rabbit and dogs revealed $80-90 \%$ of Tc- $99 \mathrm{~m}$ activity remained bound to tetracyclines [45].

In radiopharmaceuticals, Tc-99m labeled tetracycline hydrochloride has been used as a kidney scanning agent. Particular conditions have been adjusted for labeling of tetracycline hydroxide with $\mathrm{Tc}-99 \mathrm{~m}$ including neutral $\mathrm{pH}$ and $\mathrm{Sn}+2$ as a reducing agent. Chromatography is used for the investigation of using mixture of 4:1:5 n-butanol, acetic acid and water as developing solvents. Reduced Tc-99m remained at origin while labeled Tc-99m moved at $\mathrm{Rf} \approx 0.6$. Time does not have an effect on labeling while the $\mathrm{pH}$ does and maximum labeling takes place at physiological pH. Radiochromatographic, U.V visible spectrophotometric, fluorometric, conductrometric and potentiometric techniques are used for calculation of thermodynamic conditions and oxidation state of Tc- $99 \mathrm{~m}$. It is essential to use the Tc-99m which is obtained only from 99Mo/99mTcgenerator at macroscale [60].

Doxycycline hyclate is a well-known broad spectrum tetracycline antibiotic. It is obtained through the alteration of the oxytetracycline molecule which has bacteriostatic activity against a variety of microorganisms, including aerobic and anaerobic Grampositive and Gram-negative bacteria, chlamydiae, rickettsiae and mycoplasmas. It disrupts the transfer RNA and messenger RNA at ribosomal sites by inhibiting bacterial protein synthesis [41].

\section{Conclusion}

Properties of tetracycline and its analogues, such as antibacterial and non-antibacterial activities, are the cheapest and their availability, especially in developing countries, make it valuable for the treatment of various diseases. In this era, a major hazard for humans is the risk of infectious diseases, for which a range of drugs are developing and using in routine analysis. Radiation therapy is one of the more advanced methods to treat infectious lesions by using a radioisotope. Structure-activity-relationship (SAR) of tetracycline family, which shows the bioactivity, strength and selectivity to the biological target, makes it valuable for labeling with radioisotopes. Up till now there are a few numbers of analogues of tetracycline which are labeled with radioisotopes and clinically used for treatment of bacterial and non-bacterial diseases with excellent results. In future, we can plan further studies on tetracycline analogues for their radiolabeling as diagnostic and therapeutic agents.

\section{Acknowledgement}

Authors are cordially thankful to Miss. Sadia Haider for fruitful discussions and help in searching valuable literature.

\section{References}

1. Chopra I, Roberts M (2001) Tetracycline antibiotics: mode of action, applications, molecular biology, and epidemiology of bacterial resistance. Microbiology and molecular biology reviews 65(2): 232-260.

2. Fuoco D (2012) Classification Framework and Chemical Biology of Tetracycline-Structure-Based Drugs. Antibiotics 1(1): 1-13.

3. Nelson M, Ismail M (2007) The antibiotic and nonantibiotic tetracyclines. Comp. Med. Chem 7: 742-775.

4. Nelson M (1998) Chemical and biological dynamics of tetracyclines, Advances in dental research 12: 5-11.

5. Chaidemenos GC (2001) Tetracycline and niacinamide in the treatment of blistering skin diseases. Clinics in dermatology 19(6): 781-785.

6. Ramamurthy NS, Rifkin BR, Greenwald RA, Xu J -w, Liu Y, et al. (2002) Inhibition of matrix metalloproteinase-mediated periodontal bone loss in rats: a comparison of 6 chemically modified tetracyclines. Journal of periodontology 73(7): 726-734.

7. Yanagimura M, Koike F, Hara K (1989) Collagenase activity in gingival crevicular fluid and inhibition by tetracyclines. Journal of Dental Research 68: 1691-1693.

8. Fuoco D (2015) Cytotoxicity Induced by Tetracyclines via Protein Photooxidation, Advances in Toxicology.

9. Nelson ML, Levy SB (2011) The history of the tetracyclines. Annals of the New York Academy of Sciences 1241: 17-32.

10. King Eq, Lewis Cn, Welch H, Clark Ea, Johnson Jb, et al. (1950) Clinical observations on the use of Terramycin hydrochloride. Journal of the American Medical Association 143(1): 1-4.

11. Blackwood RK, Beereboom JJ, Rennhard HH, von Wittenau MS, Stephens CR (1961) 6-Methylenetetracyclines. 1 I. A new class of tetracycline antibiotics. Journal of the American Chemical Society 83(12): 27732775 .

12. Stephens CR, Beereboom JJ, Rennhard HH, Gordon PN, Murai K, et al. (1963) 6-Deoxytetracyclines. IV. 1, 2 Preparation, C-6 Stereochemistry, and Reactions. Journal of the American Chemical Society 85(17): 26432652. 
13. Mc Cormick J, Sjolander NO, Hirsch U, Jensen ER, Doerschuk AP (1957) A new family of antibiotics: the demethyltetracyclines. Journal of the American Chemical Society 79(16): 4561-4563.

14. Doerschuk AP, Bitler BA, Mc Cormick J (1955) Reversible isomerizations in the tetracycline family. Journal of the American Chemical Society 77(17): 4687-4687.

15. Sum P-E, Lee VJ, Testa RT, Hlavka JJ, Ellestad GA, et al. (1994) A new generation of potent antibacterial agents through modification of 9-aminotetracyclines. Journal of medicinal chemistry 37(1): 184-188.

16. Petersen PJ, Jacobus N, Weiss W, Sum P, Testa R (1999) In vitro and in vivo antibacterial activities of a novel glycylcycline, the 9-t-butylglycylamido derivative of minocycline (GAR-936), Antimicrobial agents and chemotherapy 43(4): 738-744.

17. Townsend ML, Pound MW, Drew RH (2011) Potential role of tigecycline in the treatment of community-acquired bacterial pneumonia. Infect Drug Resist 4: 77-86.

18. Greenwald R, Golub L, Lavietes B, Ramamurthy N, Gruber B, et al. (1987) Tetracyclines inhibit human synovial collagenase in vivo and in vitro. The Journal of rheumatology 14(1): 28-32.

19. D Agostino P, Ferlazzo V, Milano S, La Rosa M, Di Bella G (2001) Antiinflammatory effects of chemically modified tetracyclines by the inhibition of nitric oxide and interleukin-12 synthesis in J774 cell line International immunopharmacology 1(9-10): 1765-1776.

20. Amin AR, Patel RN, Thakker GD, Lowenstein CJ, Attur MG, et al. (1997) Post-transcriptional regulation of inducible nitric oxide synthase mRNA in murine macrophages by doxycycline and chemically modified tetracyclines. FEBS letters 410(2-3): 259-264.

21. Martin RR, Warr GA, Couch RB, Yeager H, Knight V (1974) Effects of tetracycline on leukotaxis. Journal of Infectious Diseases 129(2): 110 116.

22. Pruzanski W, Greenwald RA, Street LP, Lauberte F, Stefanski E, et al. (1992) Inhibition of enzymatic activity of phospholipases A2 by minocycline and doxycycline. Biochemical pharmacology 44(6): 11651170 .

23. Thong Y, Ferrante A (1979) Inhibition of mitogen-induced human lymphocyte proliferative responses by tetracycline analogues. Clinical and experimental immunology 35(3): 443-446.

24. Cosentino U, Varí MR, Saracino AG, Pitea D, Moro G, et al. (2005) Tetracycline and its analogues as inhibitors of amyloid fibrils: searching for a geometrical pharmacophore by theoretical investigation of their conformational behavior in aqueous solution. Journal of molecular modeling 11(1): 17-25.

25. Chen M, Ona VO, Li M, Ferrante RJ, Fink KB, et al. (2000) Minocycline inhibits caspase- 1 and caspase- 3 expression and delays mortality in a transgenic mouse model of Huntington disease. Nature medicine 6: 797801.

26. Yrjänheikki J, Tikka T, Keinänen R, Goldsteins G, Chan PH, et al. (1999) A tetracycline derivative, minocycline, reduces inflammation and protects against focal cerebral ischemia with a wide therapeutic window. Proceedings of the National Academy of Sciences 96(23): 13496-13500.

27. Thomas M, Le WD, Jankovic J (2003) Minocycline and other tetracycline derivatives: a neuroprotective strategy in Parkinson's disease and Huntington's disease. Clinical neuropharmacology 26(1): 18-23.

28. Duivenvoorden WC, Hirte H, Singh G (1996) Use of tetracycline as an inhibitor of matrix metalloproteinase activity secreted by human bonemetastasizing cancer cells, Invasion \& metastasis 17(6): 312-322.

29. Rubins JB, Charboneau D, Alter MD, Bitterman PB, Kratzke RA (2001) Inhibition of mesothelioma cell growth in vitro by doxycycline. Journal of Laboratory and Clinical Medicine 138(2): 101-106.

30. Stetler Stevenson W, Liotta L, Kleiner D (1993) Extracellular matrix 6 : role of matrix metalloproteinases in tumor invasion and metastasis. The
FASEB Journal 7(15): 1434-1441.

31. Ermak G, Cancasci VJ, Davies KJ (2003) Cytotoxic effect of doxycycline and its implications for tet-on gene expression systems. Analytical biochemistry 318(1): 152-154.

32. Fuoco D (2012) Classification Framework and Chemical Biology of Tetracycline-Structure-Based Drugs, Antibiotics 1(1): 1-13.

33. Golub L, Suomalainen K, Sorsa T (1992) Host modulation with tetracyclines and their chemically modified analogues. Current opinion in dentistry 2: 80-90.

34. Martin RB (1985) Tetracyclines and daunorubicin. Met Ions Biol Syst19:19-52.

35. Fuoco D (2011) Classification Framework and Structure-ActivityRelationship (SAR) of Tetracycline-Structure-Based Drugs. arXiv preprint arXiv: 1111.2769

36. Tamargo RJ, Bok RA, Brem H (1991) Angiogenesis inhibition by minocycline. Cancer Research 51: 672-675.

37. Yrjänheikki J, Keinänen R, Pellikka M, Hökfelt T, Koistinaho J (1998) Tetracyclines inhibit microglial activation and are neuroprotective in global brain ischemia. Proceedings of the National Academy of Sciences. 95(26): 15769-15774.

38. Yu LP, Smith GN, Brandt KD, Myers SL, OConnor BL, et al. (1992) Reduction of the severity of canine osteoarthritis by prophylactic treatment with oral doxycycline. Arthritis \& Rheumatism 35(10): 1150-1159.

39. Williams S, Wakisaka A, Zeng Q Barnes J, Seyedin S, et al. (1998) Effect of minocycline on osteoporosis. Advances in dental research. 12(2): 71-75.

40.Sapadin AN, Fleischmajer R (2006) Tetracyclines: nonantibiotic properties and their clinical implications. Journal of the American Academy of Dermatology 54: 258-265

41. Ozdemir DI, Asikoglu M, Özkiliç H (2010) Biodistribution of Technetium99m Doxycycline Hyclate, FABAD J. Pharm Sci 35: 185-189.

42. Kassis AI (2008) Therapeutic radionuclides: biophysical and radiobiologic principles, Seminars in nuclear medicine. Elsevier 38(5): 358-366.

43. Sugiura G, Kühn H, Sauter M, Haberkorn U, Mier W (2014) Radiolabeling strategies for tumor-targeting proteinaceous drugs. Molecules 19: 21352165 .

44. Anderson CJ, Welch MJ (1999) Radiometal-labeled agents (nontechnetium) for diagnostic imaging. Chemical reviews 99: 2219-2234.

45. Dewanjee MK, Fliegel C, Treves S, Davis MA (1960) 99 rnTC Tetracyclines: Preparation and Biological Evaluation. The Journal of Nuclear Medicine 15(3): 176-82.

46. Adler N, Camin LL, Shulkin P (1976) Rat model for acute myocardial infarction: application to technetium-labeled glucoheptonate, tetracycline, and polyphosphate, Journal of nuclear medicine: official publication. Society of Nuclear Medicine17: 203-207.

47. Holman BL, Dewanjee M, Idoine J, Fliegel C, Davis MA, et al. (1973) Detection and Localization of Myocardial Infarction with99mTcTetracycline. Investigative Radiology 8: 288.

48. Holman BL, Lesch M, Zweiman FG, Temte J, Lown B, et al. (1974) Detection and sizing of acute myocardial infarcts with 99mTc ( $\mathrm{Sn}$ ) tetracycline. New England Journal of Medicine 291:159-163.

49. Baum S (1971) The Site of Accumulation of 99mTc-Sodium Pertechnetate in Brain Tumors . Radiology 99: 153-155.

50. Tilden RL, Jackson J, Enneking WF, Deland FH, McVey JT (1973) 99mTc-polyphosphate: Histological localization in human femurs by autoradiography. Journal of Nuclear Medicine 14: 576-578.

51. Fliegel CP, Dewanjee MK, Holman LB, Davis MA, Treves S (1974) 99mTcTetracycline as a Kidney and Gallbladder Imaging Agent. Radiology 110: 407-412. 
52. Dewanjee M (1975) Autoradiography of live and dead mammalian cells with/sup 99m/Tc-tetracycline. Journal of Nuclear Medicine 16(4): 315317.

53. Albert A (1953) Avidity of terramycin and aureomycin for metallic cations. Nature 172: 201.

54. Albert A, Rees C (1956) Avidity of the Tetracy-clines for the Cations of Metals. Nature 177: 433-434.

55. Doluisio JT, Martin AN (1963) Metal complexation of the tetracycline hydrochlorides. Journal of medicinal chemistry6: 16-20.

56. Dewanjee M, Fliegle C, Davis M, Treves S (1972) Tc-99m-Labeled Tetracycline-New Radiopharmaceutical For Renal Imaging. Journal of Nuclear Medicine SOC NUCLEAR MEDICINE INC 1850 SAMUEL MORSE DR, RESTON, VA 20190-5316 pp. 427

\section{ISSN: 2574-1241}

DOI: $10.26717 / B J S T R .2018 .07 .001475$

Syed Faheem Askari Rizvi. Biomed J Sci \& Tech Res

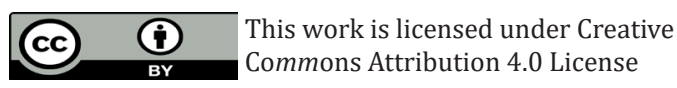

Submission Link: https://biomedres.us/submit-manuscript.php
57. Eckelman W, Meinken G, Richards P (1971) Chemical state of 99mTc in biomedical products. Journal of Nuclear Medicine 12(9): 596-600.

58. Foreman H (1960) The pharmacology of some useful chelating agents. Metal-binding in Medicine 82-94.

59. Hosain F, Reba RC, Wagner Jr HN (1969) Visualization of Renal Structure and Function with Chelated Hadionuclides. Radiology 93: 1135-1138.

60.Zurriaga AI, Domenech RG, Marti AF, Alvarez JG (1986) 99m Tctetracycline radiopharmaceutical: Physical chemistry study related to the preparation and reaction products and thermodynamic stability. International Journal of Radiation Applications and Instrumentation. Part B. Nuclear Medicine and Biology 13(6): 611-615.

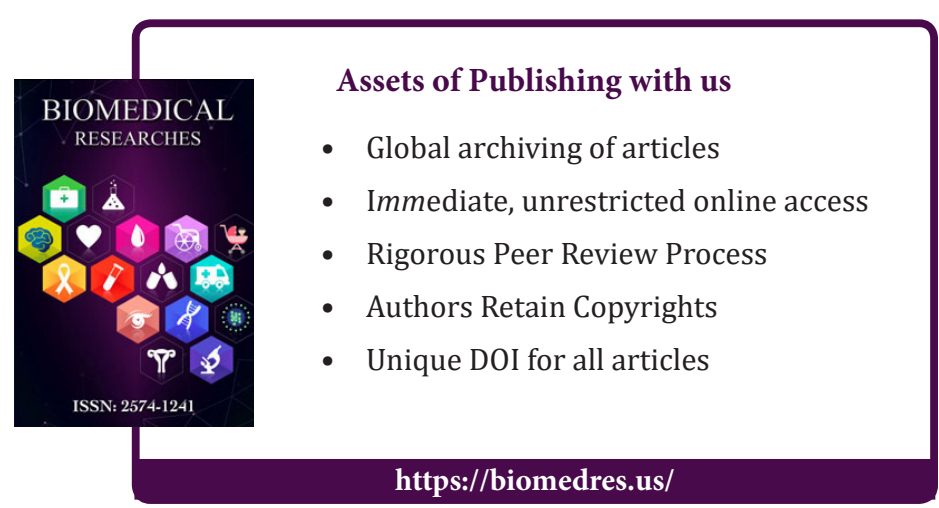

